\title{
Simbologia de AÇORIANidade na Pintura DE Domingos Rebelo e de Borba VieIRA
}

Gabriela Castro

(Universidade dos Açores)

A Açorianidade é questão que, de há três anos a esta parte, nos propusemos estudar do interior da Estética Filosófica, como projecto de investigação apoiado pela Direcção Regional da Ciência e Tecnologia, do Governo dos Açores, e que metaforicamente denominámos REMA.

REMA, acrónimo de Reflexão Estética sobre a Mundividência da Açorianidade, levou-nos às nove ilhas do arquipélago onde pudemos olhar, sentir e vivenciar o modo como a Açorianidade é, em nosso entender, uma presença subjectiva numa ausência de objectividade.

Certamente que perguntar pela Açorianidade é tarefa profícua para se apreender o desvelar de um modo de ser açoriano que não sendo regional não deixa de ser o testemunho da nossa regionalidade. Somos açorianos sim, porém, iguais e diferentes nesse mesmo modo de o sermos. Cada ilha, cada cidade, cada freguesia dos Açores se sente irmã e rival de todas as outras. Aquilo que o sentimento, a afectividade ou a emoção a todos une, rivaliza, de acordo com os mesmos pressupostos, com tudo aquilo que aos mesmos diferencia.

Pensar a Açorianidade pelos símbolos presentes nos quadros de Domingos Rebelo e de Tomaz Borba Vieira é assim o nosso tema assente numa inteligibilidade estética, porque subjectiva e onde o belo se revela uma finalidade sem fim, em sentido kantiano.

A arte é a expressão mais antiga que a humanidade conhece. O homem antes de falar, vê. Antes de escrever é afectado pelas cores, pelos sons e pelas formas. Por isso, o homem, desde os tempos mais remotos que confia aos materiais, mais estáveis do que a memória, aquilo que pensa, venera, crê, vê, diz, sonha e sente, numa palavra, aquilo que é.

Do interior do universo açoriano recorramos a Antero de Quental que entende ser a arte "a coisa santa da humanidade, nela se encontra a

Philosophica, 36, Lisboa, 2010, pp. 45-54 
conciliação da ciência e da religião, o abraço da inteligência e do coração, o nascimento da Beleza" . Mais tarde, para Heidegger, em Höldzweg, a arte é enigma, a arte "não é mais do que uma ideia de conjunto na qual nós incluímos aquilo que somente na arte é real: as obras e os artistas"2. Para Paul Ricoeur a arte encontra na imaginação criadora o seu momento de gestação, que se expressa, sobretudo, como récit, sendo este entendido como o resultado da cópula aristotélica "mythos-mímesis", ou seja, a arte é composição exigitiva de uma hermenêutica decifradora do enigma que ela esconde e que a torna essencialmente arte.

Se a arte é um enigma, a sua decifração deverá passar pelo estudo e análise dos símbolos que o artista colocou na sua obra, bem como pela captação desse momento superior da comunicação de que apenas o precipiente é capaz de se apropriar, o momento da re-criação.

Falamos de símbolo, partindo do princípio de que a inteligibilidade própria do senso comum é suficiente para captarmos a sua significação. No entanto, será que essa inteligibilidade é a que está subjacente à sua compreensão no universo filosófico? Ricoeur dedicou inúmeras páginas à tentativa de expressar esse núcleo de inteligibilidade próprio do símbolo e que faz dele matéria de reflexão filosófica com a sua célebre frase "Le symbole donne a penser". Tentemos, pois, a apreensão intelectual desse núcleo eidético que apaixonou Ricoeur colocando o quesito, simples na sua formulação literária e complexo na sua compreensão filosófica: o que é o símbolo?

Comecemos pelo sentido originário presente na etimologia da própria palavra grega. Símbolo é sinal de reconhecimento, é coisa justificativa de identidade própria ${ }^{3}$. Nesta afirmação parece-nos que o símbolo se identifica com sinal, porém, no sinal, existe uma intencionalidade clara e directa, ao passo que no símbolo à intencionalidade primeira literal, se sobrepõe uma intencionalidade segunda, captada somente a partir da primeira. É esta complexidade de intencionalidades que permite afirmar a opacidade do símbolo e a exigência da sua interpretação.

A dualidade do símbolo implica a presença actuante da imaginação criadora. A dualidade simbólica pressupõe sinais que possuem já um sentido primário, literal, manifesto, e que, por esse sentido, revelam um outro só atingível a partir do primeiro, mas que passa pela interpretação integradora do mundo vivido do intérprete e apela à sua imaginação, para colmatar o vazio que se dá entre a presença significativa do signo e a re-presentação figurativa que acompanha a interpretação simbólica.

1 Antero Quental - Obras completas, organização, introdução e notas de Joel Serrão, Universidade dos Açores, Editorial Comunicações, 1991, [37, 5-23].

2 Martin Heidegger - Chemins que ne mènent nulle part, Gallimard, Paris, 1980, p. 11, tradução portuguesa, A origem da obra de arte, Ed. 70, Lisboa, 1991, p. 11.

3 Pierre Chantraine, Dictionaire étimologique de la langue grecque, Ed. Klincksieck, Paris, 1990. 
Sigamos na esteira de Ricoeur e partamos das três regiões privilegiadas da cultura de onde emergem os símbolos ${ }^{4}$, cósmica, onírica e poética, para a análise das obras que nos propusemos interpretar. Ressalvemos, no entanto que o sujeito que interroga deve ser considerado como pertencente à realidade sobre a qual interroga, pois só deste modo, isto é, pertencendo previamente a um mundo, é que podemos interrogarmo-nos sobre o seu sentido. Esta pertença ontológica Eu-mundo é anterior e prévia à constituição do eu como sujeito face a um mundo de objectos o que torna possível um segundo movimento: a possibilidade de estabelecer uma distância, entre o eu e os actos nos quais esse mesmo sujeito se objectiva, por isso, a pertença só pode ser perspectivada pela exigência dialéctica da distanciação crítica $^{5}$, única capaz de possibilitar a captação do sentido da existência, através da interpretação dos sinais e dos símbolos que a preenchem. Por isso este estudo só poderá passar por uma hermenêutica, o mesmo é dizer por uma interpretação capaz de desvelar o sentido, a verdade e o mundo onde se insere. Esse mundo é o mundo da cultura e é de dentro desse mundo que vos trazemos duas das nossas mais paradigmáticas expressões, Os Emigrantes e Os Regressantes.

A pintura Os Emigrantes, de Domingos Rebelo ${ }^{6}$, datada de 1926, integra-se no movimento ideológico do Regionalismo, apresentado pelo Padre Ernesto Ferreira no seu opúsculo intitulado Regresso à Terra, através do qual se valorizava a importância dos usos, costumes e tradições populares na definição de culturas distintas.

Esta pintura tem a particularidade de ser a representação de um fenómeno social, muito presente nos Açores: a emigração. Esta realidade social apresenta-se como aglutinadora do conceito de "Açorianidade", analisado, na época, pelo investigador Luís Ribeiro, mais tarde retomado, em hora de afectividade por Vitorino Nemésio. Para reforçar a temática central, Domingos Rebelo regista nesta obra o trajo popular e os elementos identificativos do local de partida, juntando, nesta composição, elementos culturais de raízes profundas.

\footnotetext{
${ }^{4}$ A preocupação ricoeuriana em tentar alargar a sua base de iniciação e enumerar os pontos ou zonas onde o símbolo aflora ou emerge, não se verifica somente em $\mathrm{La}$ symbolique du mal. Em De l'interprétation: essai sur Freud, o filósofo retoma este trabalho sob a égide da epistemologia do símbolo.

5 Este conceito hermenêutico é, em relação ao de pertença, o que, na fenomenologia husserliana é a époqué em relação ao vivido. A distanciação hermenêutica implica que o sujeito só pode apropriar-se do sentido, porque este supõe uma "mise à distance" (époqué) da pertença (Lebenswelt).

De acordo com Manuel Maceiras esta noção de distância é a que possibilita o afastamento de Ricoeur de Heidegger. Cf o.c., p. 50.

6 Domingos Rebelo, nasceu em Ponta Delgada, S. Miguel, em 1891, vindo a falecer em Lisboa em1975
} 
A nosso ver, esses elementos não são apenas elementos culturais eles são símbolos perfeitamente identificadores e reveladores de um sentido segundo que apenas neles aflora e que por eles poderá ser captado. Eles são a fala de um povo, cujo referente está bem presente e envolvente na dinâmica própria do viver ilhéu.

Os Emigrantes transborda e transporta a simbologia própria de uma regionalidade explicitante de um referente cuja ausência-presente permanece para além das margens da própria pintura.

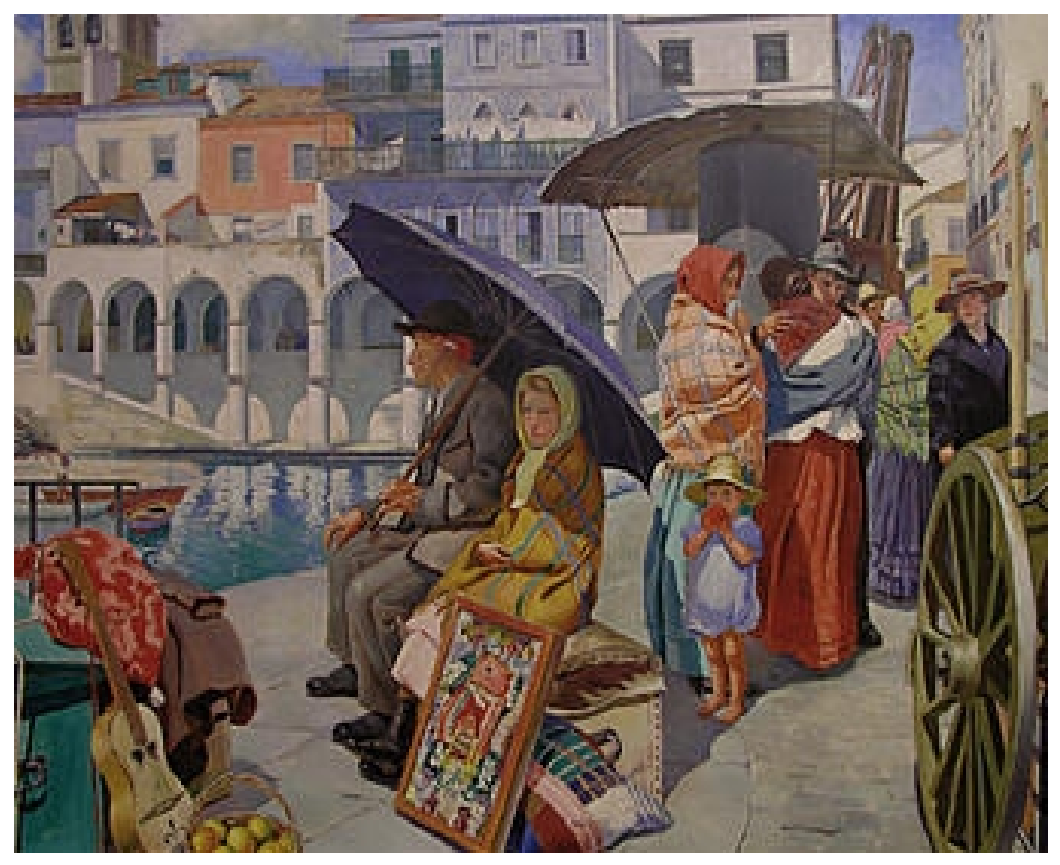

Se não vejamos:

O mar, símbolo cósmico representante de termo e de início.

Imensidade sem fim onde o horizonte sufoca qualquer hipótese real de ultrapassagem, mas linha que desafia a imaginação e o sonho de quem, preso se liberta das amarras de uma realidade concreta, limitada pela hipotética certeza dos ilimitados possíveis.

Mar é caminho, e obstáculo, é pão e fome, é amigo e por vezes carrasco. Mas o mar, para o açoriano, não é uma barreira que separa mas uma via que une, não é um obstáculo que ruge ao seu ouvido nas noites de Inverno, mas uma estrada onde os ecos dos cagarros ecoam nas lindas noites de Agosto à luz de um luar, que só nos Açores desenha figuras dantescas nas escarpas rochosas das ilhas ou nas imponentes encostas do Pico. 
O mar, neste quadro é simbolicamente o início do sonho e o termo de uma existência sofrida.

Se é no sonho que se pode surpreender a passagem da função cósmica do símbolo para a função onírica, é desta que se passa, imageticamente, para a função religiosa do símbolo. Aqui, temos o registo do Senhor Santo Cristo. Nesta pintura este pormenor possui toda a carga do simbolismo sagrado. Diz-nos Ricoeur, “É no sonho que se pode surpreender a passagem da função 'cósmica' para a função 'psíquica' dos simbolismos mais fundamentais e mais estáveis da humanidade; não compreenderíamos que o símbolo pudesse significar a ligação entre o ser do homem e o ser total, se opuséssemos (...) as hierofanias, de acordo com a fenomenologia da religião e as produções oníricas, segundo a psicanálise freudiana e junguiana (...), porque é a mesma coisa manifestar o sagrado no 'cosmos' ou na "psyche"" 7 . Esta afirmação justifica a dupla expressividade do símbolo, que simultaneamente desvela a partícula mais íntima do que somos e nos guia na procura daquilo que queremos $\operatorname{ser}^{8}$. As dimensões cósmica e psíquica, são, no fundo, dois pólos complementares da mesma expressividade, na medida em que, o homem ao expressar-se, diz o mundo e, ao decifrar a sacralidade nele existente, explora a própria dimensão sobrenatural ${ }^{9}$.

Observemos as figuras. Parecem-nos pessoas humildes, pacientes, ordeiras cordiais e aparentemente pacatas. Porém, não podemos esquecer a sua realidade concreta, vivem em cima de vulcões, conscientes da realidade física de que os mesmos podem, a qualquer momento, entrar em ebulição, mas crentes, com enorme fé, de que sobre estes nove rochedos de basalto que constantemente possuem actividade sísmica, vivem «à conta de Deus!». Esta realidade natural moldou o seu modo de ser que Domingos Rebelo tão bem expressou, calmos, cordatos, sinceros, porém, sempre que necessário assumindo-se e enfrentando o desconhecido com a mesma força anímica que lhes vem do magma incandescente que sob os seus pés borbulha aguardando a hora certa ou incerta de pelas frestas das suas paisagens paradisíacas, a qualquer momento, poder brotar. Esta certeza incerta mostra bem a dupla expressão do símbolo: cósmica e onírica, que aqui possui o seu complemento na terceira zona de emergência do símbolo, segundo Ricoeur, a poética ${ }^{10}$. Nesta, a imaginação espraia-se no

7 Paul Ricoeur, Philosophie de la volonté: II Finitude et culpabilité: 2. La symbolique du mal, Aubier, 1960, 1988, pp 19-20. A partir de agora referiremos esta obra pela sigla $S M$.

8 "Comme guide du «devenir soi-même», cf. SM, p. 20.

${ }^{9}$ Cf. $S M$, p. 20.

10 Esta terceira zona de emergência dos símbolos, nos anos sessenta, motiva em Ricoeur apenas observações pontuais. No entanto, tornar-se-á o núcleo do seu modo de inteleccionar a imaginação, marcado pela imagem-palavra face à imagem-representação, presente nas duas zonas de emergência dos símbolos que acabamos de tratar. 
infindável areal da poesia. Existe em nós um sentido escondido "que o sonho desvela o que faz de todo o sonhador um poeta"11. E poeta é aquele que ao deixar a sua terra leva consigo a sovadeira, com a merenda que the conservará o corpo e a viola que o embala nos acordes dolentes e alegres das festas, dos arraiais, das melodias que cantam a saudade em belas metáforas que, só por si, desvelam o indizível do ser, pela inovação semântica que comportam.

Símbolo é ainda As Portas da Cidade. Porta é sempre expressão de passagem por onde se entra ou se sai. E estas portas não têm porta. Carregam o simbolismo da partida e da chegada e por isso estavam edificadas logo à beira do cais de onde se partia e aonde se chegava. Nesta pintura a intencionalidade segunda deste símbolo torna presente o próprio sonho e a realidade do açoriano que, mesmo longe, possui no seu imaginário o eterno desejo de um dia regressar à sua terra, onde poderá entrar sem barreiras que o impeçam de, finalmente, ser feliz.

São os Regressantes que Tomaz Borba Vieira ${ }^{12}$ pintou, em 1987, em homenagem a Domingos Rebelo.

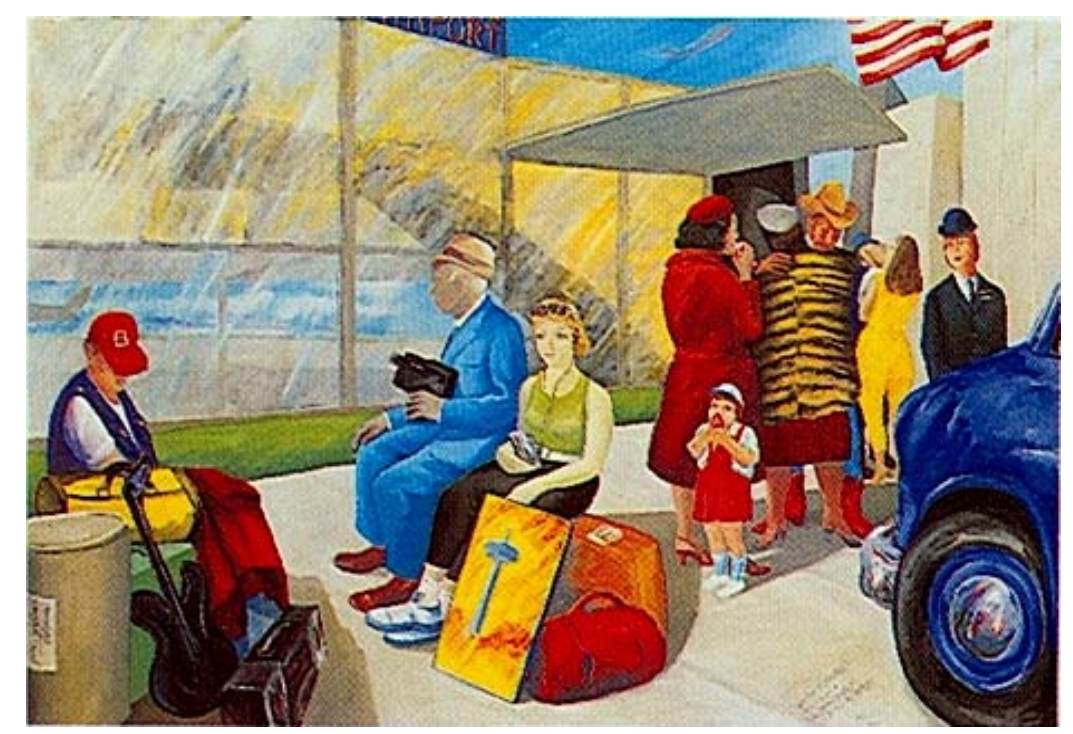

11 Paul Ricouer, De l'interprétation, essai sur Freud, Ed. du Seuil, Paris, 1965.p. 24. A partir de agora referiremos esta obra pela sigla $I e F$.

12 Tomaz Borba Vieira, pintor açoriano nascido em 1938, em Ponta Delgada, Ilha de S. Miguel. 
Nesta pintura o autor denota a metamorfose do corpo cultural na expressão do corpo-vivido dos Regressantes. A aculturação está presente, os símbolos são outros. O mar é agora uma pista de aeroporto, com uma nesga de céu azul cortada por uma coluna de fumo, qual poluição das sociedades desenvolvidas. O registo do Senhor Santo Cristo, um quadro com a CNTower de Toronto, símbolo do poder e da grandeza de uma sociedade vanguardista. A viola da terra, uma viola eléctrica com sonoridade mais apropriada aos novos estilos musicais. A sovadeira é, agora, um saco, o baú uma mala de viagem, a fruta um rádio e a figura de chapéu, que se encontrava do lado esquerdo do quadro Os Emigrantes e que denotava a consciência social do artista, é agora uma assistente de bordo, denotando a consciência social dos Regressantes. Ao alto, vislumbra-se parte da bandeira dos EUA, a carroça é já um automóvel. Se o paralelismo das figuras e dos gestos é de fácil identificação, em contextos diferentes, existe, no entanto, alguém mais nesta representação. Está presente à esquerda, de boné a tapar-lhe o rosto numa atitude de afastamento em relação a toda a cena. Este não é certamente um regressante, mas, a nosso ver, o símbolo do tempo. Nele e por ele se perspectiva a mudança. Ele é o símbolo da mesmidade na ipseidade que se vislumbra pela lente de uma câmara de filmar, virada para o futuro-passado, ou na imagem fixada pela máquina fotográfica.

Todos os símbolos são diferentes. Parece que se perdeu a Açorianidade. Mas, não fará parte dessa mesma Açorianidade a realização do sonho que deu origem à partida e ao regresso?

Tomando Os Regressantes como um todo, poderíamos identificar esta obra de arte, na esteira de Ricoeur, como um símbolo poético ${ }^{13}$.

O filósofo identifica o símbolo poético numa feliz metáfora, como imagem-verbo. A imagem-verbo é a palavra capaz de representar e de expressar a criatividade própria do poeta. Sem a imagem-verbo, o excedente da linguagem seria mais excedente, pois aquilo que é dito ficaria para sempre escondido nas entranhas do pensamento e do sentimento do próprio sonhador, do próprio poeta. O poeta é aquele que, com a palavra e pela palavra, nos transporta para fora do nosso próprio existir e nos coloca algures, ou talvez nenhures, numa abertura aos possíveis criados pela imaginação. Numa visão bastante influenciada por Heidegger, em $A$ origem da obra de arte, diríamos que o poema, ou a poesia, é o momento

13 Sérgio de Gouvêa Franco é da opinião que "os símbolos poéticos deveriam ter sido estudados em outro livro de sua série Philosophie de la volonté, que jamais foi produzido", in Sérgio de Gouvêa Franco, oc. p. 59. Esta não é a nossa maneira de inteleccionarmos o possível percurso filosófico de Ricoeur, como tentaremos demonstrar na nossa alínea intitulada "Para uma não-poética da vontade". No entanto, podemos reconhecer que também Sérgio de Gouvêa Franco, indirectamente, centra a sua defesa de uma Poética da Vontade na imaginação. 
revelador da verdade do ser. Ser poeta é conseguir captar e expressar o momento originário e emergente do próprio ser não apenas pela linguagem, mas por toda e qualquer expressão capaz de revelar e desvelar um sentido e uma significação. É nesta linha de interpretação que entendemos Os Regressantes como símbolo poético, como a imagem-criação, que ilumina e desvela a inteligibilidade do momento da presença nascente do $\operatorname{ser}^{14}$. Esta é a tarefa do artista, do pintor: tornar visível a invisibilidade do ser primordial, e unir artista, obra e percipiente, diria Merleau-Ponty.

Ora, a criatividade dá-se quando o artista é capaz de colocar um certo conteúdo numa determinada forma ou expressão, de modo a despoletar, tendo em conta o respectivo universo ontológico, o belo ou o sentimento do belo. Este conteúdo se, para Freud, é produto das fantasias inconscientes do artista, para Kant, encontra a sua razão de ser nas ideias estéticas da imaginação ${ }^{15}$. É esta imaginação genial a faculdade originariamente criadora da arte, pois nela as ideias estéticas brotam da prenhez anímica do artista. Esta plenitude de alma necessita de vir à fala, e o modo como o artista o faz, independentemente do meio, é o símbolo.

Retomemos os símbolos, como "expressões de duplo ou de múltiplo sentido cuja textura semântica é correlativa ao trabalho de interpretação capaz de explicitar o sentido segundo ou os sentidos múltiplos, nelas escondido"16. Estes fazem aparecer um sentido novo e com eles o irrepresentado.

É sobre esta caracterização de símbolo, em Paul Ricoeur, que assenta a nossa convicção de que a obra de arte é criada e composta por símbolos, na medida em que os sinais, o traço, o som, a cor ou a palavra, são símbolos pois manifestam no seu visado uma intencionalidade dupla, atendendo a que prestam o seu sentido directo e primário à detecção de um sentido secundário, o sentido daquilo que o artista quer expressar. Assim, cada símbolo explicita o mundo vivido do artista na sua obra, tornando-a sua pertença ${ }^{17}$ intrínseca. Ou seja: a obra é explicitante, neste momento da nossa reflexão, do mundo vivido, Lebenswelt, do génio, pelo que, a criação artística encontra, no e pelo símbolo, o veículo capaz de revelar o sentido da sua originalidade. Mas, uma questão se nos levanta:

14 Esta nossa afirmação está altamente influenciada pela obra de Heidegger, Sobre a essência da Verdade, trad. de Carlos Morujão, Porto Editora, Porto, 1995.

15 Cf. Immanuel Kant - Crítica da faculdade do juízo, Imprensa Nacional Casa-da-Moeda, Lisboa, 1992, § 49. Cf. La métaphore vive, Ed. du Seuil, Paris, 1975, pp 383-384, traduzido para português com o título A metáfora viva, introdução de Miguel Baptista Pereira, trad. de Joaquim Torres Costa e António M. Magalhães, Rés Ed., Porto, 1983, p 458.

16 Cf. IeF, p. 22.

17 Remetemos para a noção de pertença em Paul Ricoeur, SM, p. 327. 
será a obra de arte só denotação do mundo vivido do artista, ou será a obra de arte o momento capaz de fazer eclodir um real que ela mesma esconde e simultaneamente revela? O mesmo é perguntar: poderá a obra de arte ser um símbolo em si mesma?

Numa tentativa de respondermos a esta questão, levantemos, para terminar, um último quesito: como é traduzida a semântica da obra de arte?

Ao quesito que acabamos de formular, podemos responder, na esteira do pensamento de Paul Ricoeur: a semântica da obra de arte encontra a sua tradução no cruzamento de duas metodologias: a hermenêutica e a fenomenológica. Por um lado, a semântica da obra de arte oferece-se na expressão do seu sentido, na medida em que a obra permite fazer jogar a polissemia dos seus símbolos no interior da sua unidade de forma e conteúdo, de modo a expressar um sentido secundário somente captável a partir dela própria como sentido primário. Por outro lado, esse sentido que se desprende de uma interpretação da obra encontra a sua autenticidade, a sua novidade, na consciência do espectador que a olha.

A arte é pois o campo em que os dois métodos filosóficos, a hermenêutica e a fenomenologia, se cruzam por excelência ${ }^{18}$. Ela é simultaneamente o lugar dos símbolos ou do sentido duplo e o lugar onde se defrontam as diversas maneiras de interpretar ${ }^{19}$. Nela se esvanecem os conflitos das interpretações. A semântica da obra de arte passa necessariamente pela interpretação da obra como símbolo, ou seja, como estrutura de duplo sentido que se oferece à intencionalidade da consciência que a percepciona.

O verdadeiro sentido estético é captado pela e na simultaneidade do mostrar-esconder da obra. Generalizando o postulado de referência, que Ricoeur aplica ao texto, a toda a obra de arte, diremos que não nos contentamos com o que a obra mostra: a sua imediatez, a sua estrutura, o seu sentido primário, o seu tema; mas pressupomos um mundo da obra que ela revela na opacidade do seu aparecer, a sua referência ou denotação.

Por este fenómeno do duplo sentido, a obra transcende-se a si própria fazendo aparecer uma realidade exterior. É pois na sua dimensão de

$18 \mathrm{Na}$ esteira de Paul Ricoeur podemos afirmar que existe na verdade, e na arte isso é notório, entre a hermenêutica e a fenomenologia uma pertença mútua, que Michel Renaud coloca nestes termos: pertença da hermenêutica à fenomenologia [na medida em que] "a fenomenologia fica a insuperável pressuposição da hermenêutica, de tal modo que a hermenêutica se edifica na base da fenomenologia, e pertença da fenomenologia à hermenêutica [na medida em que] a fenomenologia não pode constituir-se sem a pressuposição hermenêutica". In "Fenomenologia e Hermenêutica, o Projecto Filosófico de Paul Ricoeur", in Revista Portuguesa de Filosofia, tomo XLI - 4-1985, Faculdade de Filosofia de Braga, 1985, pp. 428-29.

19 CF. Paul Ricouer, Le conflit des interprétations, essais d'herméneutique I, Ed. du Seuil, Paris, 1969, p. 18. 
símbolo que a obra se coloca como objecto enigmático a explorar e suscita no espectador um questionamento que diz respeito à realidade a que ela faz referência.

Concluímos afirmando que é esta relação entre a obra de arte, o mundo da obra e o mundo do percipiente, feita pelo processo de simbolização que a obra ocasiona e que a imaginação suporta, que é responsável pelo aparecimento do belo. Estas são duas belas obras de arte onde a Açorianidade está presente. $\mathrm{O}$ mundo que assim se desvela em frente do nosso olhar e que de um modo assertivo se implanta nas nossas relações culturais próprias de um corpo-consciência-interpretante transporta toda a indizibilidade do que Gabriel Marcel denominou mystère ${ }^{20}$.

Há que interpretar os símbolos nos quais o açoriano se objectiva. Somente através da sua interpretação se abrirá o possível acesso aos actos fundantes do que somos e se constituirá o aumento da nossa consciência colectiva.

\section{ABSTRACT}

This paper tries to show, through examples from Azores paintings, in particular in the works of Domingos Rebelo and Borba Vieira, some of the fundamental categories of aesthetics and hermeneutics of painting.

Keywords: Painting, Azores

20 Gabriel Marcel mantém na sua obra uma profunda reverência ao mistério da vida e Ricoeur aprende com o seu mestre a rejeitar os reducionismos que pretendem explicar integralmente o homem e a cultura. Ouçamos Marcel: "A esta altura devemos fazer um ataque directo a certos tipos de formulações gerais do tipo «isto é somente isso..., ou isto não passa disto», ou coisas do género. Cada reducionismo depreciatório desta natureza está baseado no ressentimento, ou seja, numa paixão que tem por base um violento ataque directo contra toda a integridade do real". Cf. Gabriel Marcel - Man Against Mass Society. Trad. G. S. Fraser, Regnery, Chicago, 1964, p. 156. 